\title{
Whole genome sequencing of Mycobacterium tuberculosis isolates and clinical outcomes of patients treated for multidrug-resistant tuberculosis in Tanzania
}

Bugwesa Z. Katale ${ }^{1,2+}$, Peter M. Mbelele ${ }^{3,4+}$, Nsiande A. Lema ${ }^{5}$, Susana Campino ${ }^{6}$, Stephen E. Mshana ${ }^{7}$, Mark M. Rweyemamu ${ }^{8}$, Jody E. Phelan ${ }^{6}$, Julius D. Keyyu ${ }^{2}$, Mtebe Majigo $^{1}$, Erasto V. Mbugi ${ }^{9}$, Hazel M. Dockrell ${ }^{6}$, Taane G. Clark ${ }^{6,10}$, Mecky I. Matee ${ }^{1 *}$ (D) and Stellah Mpagama ${ }^{3}$

\begin{abstract}
Background: Tuberculosis (TB), particularly multi- and or extensive drug resistant TB, is still a global medical emergency. Whole genome sequencing (WGS) is a current alternative to the WHO-approved probe-based methods for TB diagnosis and detection of drug resistance, genetic diversity and transmission dynamics of Mycobacterium tuberculosis complex (MTBC). This study compared WGS and clinical data in participants with TB.

Results: This cohort study performed WGS on 87 from MTBC DNA isolates, 57 (66\%) and 30 (34\%) patients with drug resistant and susceptible TB, respectively. Drug resistance was determined by Xpert ${ }^{\circledR}$ MTB/RIF assay and phenotypic culture-based drug-susceptibility-testing (DST). WGS and bioinformatics data that predict phenotypic resistance to anti-TB drugs were compared with participant's clinical outcomes. They were 47 female participants (54\%) and the median age was 35 years (IQR): 29-44). Twenty (23\%) and 26 (30\%) of participants had TB/HIV coinfection $\mathrm{BMl}<18 \mathrm{~kg} / \mathrm{m}^{2}$ respectively. MDR-TB participants had MTBC with multiple mutant genes, compared to those with mono or polyresistant TB, and the majority belonged to lineage 3 Central Asian Strain (CAS). Also, MDRTB was associated with delayed culture-conversion (median: IQR (83: 60-180 vs. 51:30-66) days). WGS had high concordance with both culture-based DST and Xpert ${ }^{\oplus}$ MTB/RIF assay in detecting drug resistance (kappa $\left.=1.00\right)$.

Conclusion: This study offers comparison of mutations detected by Xpert and WGS with phenotypic DST of M. tuberculosis isolates in Tanzania. The high concordance between the different methods and further insights provided by WGS such as PZA-DST, which is not routinely performed in most resource-limited-settings, provides an avenue for inclusion of WGS into diagnostic matrix of TB including drug-resistant TB.
\end{abstract}

Keywords: Whole genome sequence, Mycobacterium tuberculosis, Multidrug-resistant tuberculosis, Time-to-cultureconversion, Treatment-outcomes

\footnotetext{
* Correspondence: mateemecky@yahoo.com

${ }^{\dagger}$ Bugwesa Z. Katale and Peter M. Mbelele contributed equally to this work.

${ }^{1}$ Department of Microbiology and Immunology, School of Medicine,

Muhimbili University of Health and Allied Sciences (MUHAS), Dar es Salaam,

Tanzania

Full list of author information is available at the end of the article
}

(c) The Author(s). 2020 Open Access This article is distributed under the terms of the Creative Commons Attribution 4.0 International License (http://creativecommons.org/licenses/by/4.0/), which permits unrestricted use, distribution, and reproduction in any medium, provided you give appropriate credit to the original author(s) and the source, provide a link to the Creative Commons license, and indicate if changes were made. The Creative Commons Public Domain Dedication waiver (http://creativecommons.org/publicdomain/zero/1.0/) applies to the data made available in this article, unless otherwise stated. 


\section{Background}

Tuberculosis (TB), caused by the Mycobacterium tuberculosis complex (MTBC), is the leading cause of mortality, killing about 2 million people each year globally [1]. The highest TB mortality and morbidity occurs in low and middle income countries like Tanzania [1, 2]. HIV infection is the most important single predictor of $\mathrm{TB}$ incidence across the African continent [3]. This is critical because HIV/AIDS is likely to increase in the risk of progression TB infection by 30 times, due to impairment on the immune system [3]. Sub-Saharan Africa carries a disproportionate burden of HIV, accounting for more than $70 \%$ of the global burden of infection [4]. For instance, in 2017, nearly 2.5 million people who contracted TB lived in sub-Saharan Africa, and 665,000 of them died from the disease [5]. The recent introduction of the Xpert ${ }^{\circ} \mathrm{MTB} /$ Rif assay (Cepheid, USA) has shown an increase in detection of drug resistance TB patients and the detection of multidrug-resistant TB (MDRTB) has increased three- to eight-fold compared to conventional testing [6]. Despite the gaps in documentation of MDRTB cases in several Sub-Saharan African countries (SSA), pooled analysis that involved several studies reported a prevalence of $2.1 \%$ of MDR-TB in new cases, signifying a low prevalence of MDR-TB cases in SSA [7]. The relatively low prevalence of MDRTB in SSA might be attributed by the recent introduction of rifampicin in Africa, by the use of rifampicin-free treatment regimens in the continuation phase (during months three to eight), by the growing use of directly observed treatment as recommended under the directly observed treatment, short course (DOTS) strategy, and by the use of fixeddose combination tablets in a few countries $[8,9]$.

Tanzania is among African countries south of Sahara with the highest burdens of TB, with an estimated 295 TB cases per 100,000 adults. The National antituberculosis drug resistance survey conducted in 2010 in Tanzania found the resistance to any of the four firstline drugs in new patients to be $8.3 \%$, while the prevalence of MDR-TB was $1.1 \%$. However, the crude prevalence for any resistance and for MDR-TB in retreated cases increased to 20.6 and $3.9 \%$ respectively [10].

The emergence of resistant strains of MTBC to antituberculosis drugs like rifampicin (RIF), isoniazid (INH), pyrazinamide (PZA), ethambutol (EMB), streptomycin (SM) among others; and the emergence of HIV in the 1980s led to resurgence of TB [11]. Multidrug resistant TB (MDR-TB), defined as resistance to at least RIF and $\mathrm{INH}$, is usually caused by MTBC strains that harbour mutations in $r p o B, k a t G$ and $i n h A$ genes associated with RIF and INH resistance. Globally, MDR-TB claims over 580,000 people's lives annually [12]. About 10\% of MDR$\mathrm{TB}$ isolates exhibit resistance to fluoroquinolones (FQs) and second-line-injectable drugs (SLIDs) (aminoglycosides/ cyclic-polypeptides), referred to as extensive drug resistant TB (XDR-TB), which challenges clinical management [2, 13, 14]. Patients with XDR-TB are infected with MTBC that have mutations in $r r s$, tlyA or eis promoter region (SLI related) and gyrA or gyrB genes (FQ related). Clinical management of both MDR-TB and XDR-TB is very complex and there are different treatment regimens [15]. About 50 and $70 \%$ of patients treated for MDR-TB and XDR-TB have unfavourable treatment outcomes, respectively. Although XDR-TB is rare in Tanzania, cohort review reports of patients treated for MDR-TB show that treatment success is only $75 \%$. However, control and prevention measures should be strengthened in the country to reduce MDRTB related morbidity and mortality. To improve treatment outcomes and control escalation of MDR/XDR-TB; early, rapid and accurate diagnostic methods are required to detect and decipher susceptibility profile of the MTBC to anti-TB drugs in TB endemic settings such as Tanzania.

As in other TB endemic settings, Tanzania has deployed rapid molecular methods for dual detection of MTBC and susceptibility to either RIF alone or along with INH and second-line injectable and fluoroquinolones. For example, while the Xpert ${ }^{\circ} \mathrm{MTB} / \mathrm{Rif}$ assay (Cepheid, USA) detects MTBC and provides information about susceptibility to RIF only [16], the genotype MTBDRplus and MTBDRsl assays (Hain Life sciences, Germany) detect mutations that are strongly associated with multiple types of MDR-TB and also $\mathrm{XDR}-\mathrm{TB}$ respectively $[17,18]$. These assays have potential to guide implementation of the new WHO shorter regimen for treating MDR-TB [15, 19]. Unlike Whole genome sequencing (WGS), these PCR-probe based assays have limited anti-TB drug-susceptibility value especially if mutations occur outside the target region [20]. In recent years, WGS platforms have become an alternative diagnostic in addressing probebased assay limitations. WGS can identify genotypes predictive of drug-resistance phenotype within the entire region of microbial genome and has potential to determine genetic relatedness and identify transmission dynamics necessary in guiding clinical decisions. There is a need to sequence as many MTBC strains as possible, build libraries of single nucleotide polymorphisms (SNPs) and other variants, compare the relatedness of MTBC strains, and correlate variation with clinical progress or outcomes as a whole. Based on this, we performed WGS for the first time on isolates sourced from patients treated for MDR-TB at Kibong'oto Infectious Diseases Hospital (KIDH) in Tanzania. These data will provide a baseline set of the types and variations in TB in Tanzania. Clinical and laboratory information such as treatment regimen, phenotypic susceptibility profile, prior history of treatment with first line anti-TB drugs, HIV status, 
culture conversion rate and treatment outcomes were available for analysis.

\section{Results}

Baseline demographic and clinical characteristics of study participants

A total of 87 study participants with positive MTBC culture results were included in the genetic study of whom, 47 (54\%) were females. The median age was 35 (Interquartile range $=29-44)$ years (Table 1$)$. Twenty $(23 \%)$ were co-infected with HIV and had a median CD4 counts of 246 (IQR $=119-388)$ cells $/ \mathrm{mm}^{3}$.

\section{Association of clinical information with genetic drug resistance}

Table 2 summarizes demographic and clinical characteristics of TB patients. We found association between previous history of TB treatment and phenotypic drug resistance (OR, 0.01 95\% CI: 0.0003-0.0995, $p=<0.001$ ) (Table 2).

\section{Analysis of mutations associated with phenotypic drug resistance to anti-TB drugs}

Of the 87 MTBC isolates sequenced, 57 (65.5\%) had at least one mutation in a gene that was predictive for 7

Table 1 Demographic and clinical information of study participants

\begin{tabular}{|c|c|c|}
\hline Variable & $\mathrm{N}$ & $\%$ \\
\hline \multicolumn{3}{|l|}{ Gender } \\
\hline Male & 40 & 46 \\
\hline Female & 47 & 54 \\
\hline \multicolumn{3}{|c|}{ Age category (years) } \\
\hline$<33$ & 31 & 35.6 \\
\hline$\geq 33$ & 56 & 64.4 \\
\hline \multicolumn{3}{|l|}{ HIV status } \\
\hline Negative & 67 & 77 \\
\hline Positive & 20 & 23 \\
\hline \multicolumn{3}{|l|}{ Diabetic } \\
\hline Yes & 1 & 1.2 \\
\hline No & 86 & 98.8 \\
\hline \multicolumn{3}{|c|}{ Previous history of TB treatment } \\
\hline New & 45 & 51.7 \\
\hline Retreatment & 42 & 48.3 \\
\hline \multicolumn{3}{|c|}{ CD4 count $(n=20)$} \\
\hline$<200$ & 8 & 40 \\
\hline$\geq 200$ & 12 & 60 \\
\hline \multicolumn{3}{|c|}{ Body mass index } \\
\hline$<16-18.5$ & 26 & 29.9 \\
\hline$\geq 18.5$ & 61 & 70.1 \\
\hline
\end{tabular}

anti-drugs (Table 3). The concordance between phenotypic DST and WGS was 97\% for RIF (DST: WGS; 26:28 isolates), 81\% INH (DST: WGS; 40:51 isolates) and 95\% for SM (DST: WGS; 8:11 isolates) (kappa $=1.00)$. Moreover, the concordance between Xpert $^{\oplus}$ MTB/RIF (Cepheid, USA) and WGS for detection of RIF resistance was $95 \%(8: 11$ isolates $)($ kappa $=1.00)$. Substitution of serine to threonine at codon 315 (S315T) of the katG gene accounted for 50 (94.3\%) of mutations (Table 3). The common mutation associated with phenotypic resistant to RIF was S450L (substitution of serine to leucine) accounted for 96\% (26/27) of the detected RIF resistance. Of the 57 isolates, 29 (33\%) had mutations in the $e m b B$ gene and Q497R was the common mutation $(8 / 29 ; 27.6 \%)$ (Table 3$)$. Nineteen isolates had mutations, in pncA genes of which V128G was the common accounting for 7 (36.8\%) (Table 3). In addition, our analysis revealed pncA deletion involving Rv2044c in two drug resistance isolates (MDRTB \& polyresistance isolates) that contributed 5.3\% (1 isolates) of MDRTB and other resistance pattern (Table 3). Patients with MDR-TB had highly diverse mutations as compared to monoresistance (Table 3 ). We found 2 pre patients harbouring XDRTB isolates. The drug resistance mutations involving either rrs or gyrB genes against $A M K$ and FQs respectively were detected in low proportions among DR resistance isolates (Table 3). These isolates had mutation either at the rrs gene involving substitution of $\mathrm{C}$ to $\mathrm{T}$ at codon 51 (C517T) or gyrB gene which involved replacement of $\mathrm{R}$ by $\mathrm{C}$ at codon 446 (R446C). MTBC isolates from drug susceptible patients had no mutations in genes encoding for INH, RFP, PZE, STM and EMB.

\section{Treatment outcome and culture conversion rates among the drug resistance TB isolates}

Of the 57 study participants with mutation (s) to at least one of the anti-TB drugs, 47 (82.5\%) had successful treatment, 3 (5.3\%) died, and 7 (12.3\%) defaulted (Table 4). Three patients (2MDR-TB and 1 with polyresistant) died 9 months after enrolment, during which they were in a continuous phase of anti-mycobacterial medications. The median (IQR) culture conversion rates were 51 (30-66) days and 83 (60-180) days for participants with mono/polyresistant and MDR/XDR-TB, respectively (Table 4 ).

\section{Phylogenetic analysis of the drug resistance TB isolates} Phylogenetic analysis revealed that the DR-TB strains were heterogeneously distributed in lineages 1 to 7 (Fig. 1). The Central Asian Strains (CAS) (lineage 3) predominated in the MTBC strains and accounted for $48.3 \%(42 / 87)$ of the isolates, followed by lineage $4(32 /$ $87 ; 36.8 \%)$, lineage $1(10 / 87 ; 11.5 \%)$, lineage $2(3 / 87$; $3.4 \%)$ and $1(1.1 \%)$. Of the 24 MDR isolates, $15(62.5 \%)$ 
Table 2 Demographic and clinical characteristics of drug resistance TB patients

\begin{tabular}{|c|c|c|c|c|}
\hline Variables, n (\%) & $\mathrm{DR}-\mathrm{TB}(n=57)$ & DS-TB $(n=30)$ & OR (95\% C.I) for DR-TB & $p$ values \\
\hline \multicolumn{5}{|l|}{ Gender } \\
\hline Male & 26 & 14 & $0.96(0.36-2.56)$ & 0.93 \\
\hline Female & 31 & 16 & & \\
\hline \multicolumn{5}{|l|}{ Age (years) } \\
\hline$<33$ & 21 & 10 & & \\
\hline$\geq 33$ & 36 & 20 & $1.17(0.42-3.34)$ & 0.55 \\
\hline \multicolumn{5}{|l|}{ HIV status } \\
\hline Negative & 41 & 26 & $2.5(0.70-11.47)$ & 0.12 \\
\hline Positive & 16 & 4 & & \\
\hline \multicolumn{5}{|c|}{ CD4 count $(n=20)$} \\
\hline$<200$ & 6 & 2 & & \\
\hline$\geq 200$ & 10 & 2 & $0.6(0.04-10.62)$ & 0.65 \\
\hline \multicolumn{5}{|c|}{ Previous history of TB treatment } \\
\hline New & 16 & 29 & $0.01(0.0003-0.0995)$ & $<0.001$ \\
\hline Retreatment & 41 & 1 & & \\
\hline \multicolumn{5}{|l|}{ Body mass index } \\
\hline$<16-18.5$ & 19 & 7 & & \\
\hline$\geq 18.5$ & 38 & 23 & $1.6(0.55-5.34)$ & 0.33 \\
\hline
\end{tabular}

isolates belonged to lineage 3 (CAS), 5 (20.8\%) isolates were lineage 4 (Latin American Mediterranean, LAM), 2 (8.3\%) isolates were lineage 2 and 2 (8.3\%) isolates originated from lineage 1 (East African Indian, EAI) (Table 5).

\section{Discussion}

In this study, we found high concordance between WGS and conventional culture-based DST in predicting phenotypic drug resistance to anti-TB drugs, ranging from $81 \%$ for INH to $97 \%$ for RIF, and $95 \%$ concordance with Xpert $^{\oplus}$ MTB/RIF (Cepheid, USA) for RIF. These findings are in agreements with those previously reported in different TB endemic settings [21-24]. The ability of $\mathrm{Xpert}^{\oplus} \mathrm{MTB} / \mathrm{RIF}$ and phenotypic detection of TB drug resistance cannot be underscored as it can pave a way to complementary and confirmatory WGS in early detection of resistance. Studies have shown phenotypic susceptibility tests to serve as reference standards [25], and that both Xpert assay and DST can provide information on polyresistance in pre- XDR-TB [26] despite varying sensitivities [27, 28].

The current practice in diagnosing drug resistant tuberculosis is through the WHO-approved probe-based assays like Xpert $^{\oplus}$ MTB/RIF (Cepheid, USA) for RIF [16] and either genotype MTBDRplus for RIF and INH or genotype MTBDRsl (Hain Lifesciences, Germany) for aminoglycosides/capreomycin and fluoroquinolones that must be confirmed with culture-based DST [29]. Unlike WGS, these assays not only have limited DST range to identify hot-spot resistant determining regions but they also cannot inform transmission dynamics [30, 31]. The high concordance supports adoption of WGS as an alternative diagnostic tool to complement results from DST of all previously treated presumptive or confirmed rifampicin resistance cases in clinical settings. Although the facilities are not yet available the approach can be advocated in future clinical settings to enable reduction in unnecessary laboratory diagnostic time delays between identification of patients suspected of MDR-TB and initiation of treatment [29]. The potential for WGS to provide a rapid and comprehensive view of the genotype and reliable prediction of the drug susceptibility phenotype has been reported elsewhere [23, 32, 33]. This is an important platform to inform about susceptibility profile drugs like pyrazinamide (PZA), which is prescribed empirically in Tanzania and other resource limited countries. PZA kills semi-dormant bacilli and has synergetic activity with bedaquiline (BDQ), a key core drug in the currently recommended all-oral injectable free MDR-TB regimen(s). This synergism supports design of a shortened treatment regimens, which favours healthy patient outcomes [34].

In our study, the WGS uncovered 2 pre patient harbouring XDR-TB isolates, which were also detected by phenotypic DST at our hospital and later cured after MDR-TB treatment. This finding adds value to WGS as a potential molecular tool to complement phenotypicDST and other molecular assay such Gene Xpert ${ }^{\bullet}$ MTB/ RIF (Cepheid, USA) MDR-TB results for informed 
Table 3 Frequency and distribution of mutations associated with drug resistance M. tuberculosis

\begin{tabular}{|c|c|c|c|c|c|c|}
\hline Drug & Target gene & mutation & n (\%) in monoresistance & $\mathrm{n}(\%)$ in MDR-TB strains & $\mathrm{n}(\%)$ in other resistance pattern & Total (N) \\
\hline \multirow[t]{2}{*}{$\operatorname{RIF}(n=27)$} & $r p o B$ & S450L & $4(14.8)$ & $16(59.3)$ & $6(22.2)$ & 26 \\
\hline & & D435Y & $1(3.7)$ & $1(3.7)$ & - & 1 \\
\hline \multirow[t]{5}{*}{$\mathrm{INH}(n=55)$} & katG & S315T & $10(18.2)$ & $24(43.6)$ & $16(29.1)$ & 50 \\
\hline & & S302R & - & $1(1.8)$ & $1(1.8)$ & 2 \\
\hline & & N138S & - & $1(1.8)$ & - & 1 \\
\hline & oxyR'-ahpC & C52T & - & $1(1.8)$ & - & 1 \\
\hline & & C54T & - & $1(1.8)$ & - & 1 \\
\hline \multirow[t]{11}{*}{$\operatorname{EMB}(n=29)$} & $e m b B$ & Y319C & - & - & $1(3.4)$ & 1 \\
\hline & & Q497R & - & $6(20.9)$ & $2(6.9)$ & 8 \\
\hline & & G406D & - & - & $1(3.4)$ & 1 \\
\hline & & G406S & - & $2(6.9)$ & $3(10.3)$ & 5 \\
\hline & & M306L & - & $1(3.4)$ & - & 1 \\
\hline & & M306I & - & $1(3.4)$ & - & 1 \\
\hline & & G406A & - & $3(10.3)$ & - & 3 \\
\hline & & M306V & - & $2(6.9)$ & - & 2 \\
\hline & & Y334H & - & $1(3.4)$ & - & 1 \\
\hline & & M306T & - & $1(3.4)$ & - & 1 \\
\hline & $E m b C-e m b A$ & C16T & 1 & $1(3.4)$ & $3(10.3)$ & 5 \\
\hline \multirow[t]{11}{*}{$\mathrm{PZA}(n=19)$} & PncA & V128G & - & $8(42.1)$ & - & 8 \\
\hline & & A193AT & - & - & $1(5.3)$ & 1 \\
\hline & & G17D & - & - & $1(5.3)$ & 1 \\
\hline & & D8N & 1 & - & - & 1 \\
\hline & & L85P & - & - & $1(5.3)$ & 1 \\
\hline & & $\mathrm{A} 46 \mathrm{~V}$ & - & $1(5.3)$ & - & 1 \\
\hline & & P69L & - & $1(5.3)$ & - & 1 \\
\hline & & Q10R & - & $1(5.3)$ & - & 1 \\
\hline & & D49G & - & $1(5.3)$ & - & 1 \\
\hline & & D63A & - & $1(5.3)$ & - & 1 \\
\hline & & Rv2044c & - & $1(5.3)$ & $1(5.3)$ & 2 \\
\hline \multirow[t]{2}{*}{$\operatorname{STR}(n=3)$} & rpsL & K43R & - & $2(100)$ & - & 2 \\
\hline & rrs & C517T & - & $1(100)$ & - & 1 \\
\hline FLO $(n=1)$ & gyr $B$ & R446C & - & $1(100)$ & - & 1 \\
\hline AMK $(n=2)$ & rrs & C517T & - & $2(100)$ & - & 2 \\
\hline
\end{tabular}

decision-making prior to anti-tuberculosis therapy. For effective use particularly in low- and middle-income countries, WGS must be robust, easy to use, and affordable.

We also found that the majority of the MTBC isolates from DR-TB participants had mutations in genes predictive of phenotypic resistance to all 7 anti-TB drugs tested including INH (katG), RIF (rpoB), EMB (embB, embC$e m b A), F Q s(g y r B)$ and second line injectable drugs ( $r r s)$ (Table 3). The commonest mutations found in this study was S450L for rpoB (26/27), S315T on katG (51/56), Q497R (8/29) and G406S (5/29) on embB, C16T (5/29) on
embC-embA, V128G (7/19) on pncA and K43R on rpsL genes are in keeping with findings reported elsewhere [35, 36]. As expected, patients with MDR-TB had multiple mutations in these genes, confirming the previous concept that drug resistance in mycobacteria spp., and other bacteria evolves as they accumulate mutations either de novo or after multiple and longer exposure to antibiotics [37, 38]. This high diversity of mutations among DR-TB patients suggests on-going transmission of MDR-TB strains rather than acquisition through random mutation and selection of drug resistance strains [37, 39]. In addition, our analysis revealed a large deletion that involved Rv2044c in 


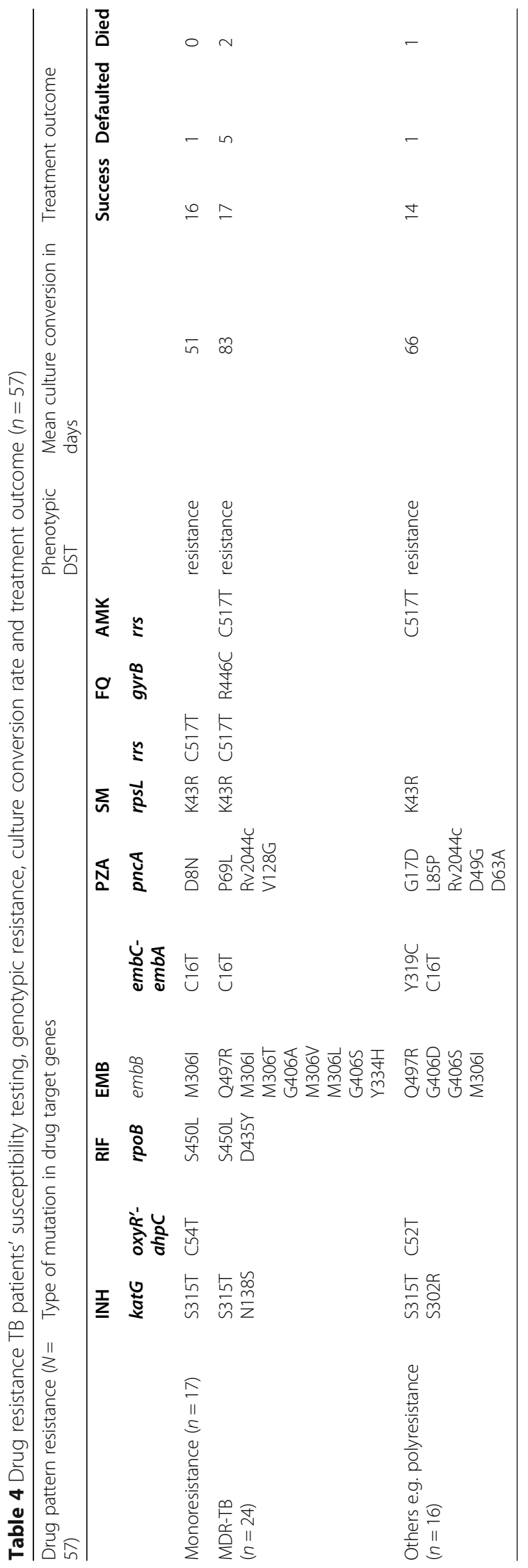


Tree scale: 0.0
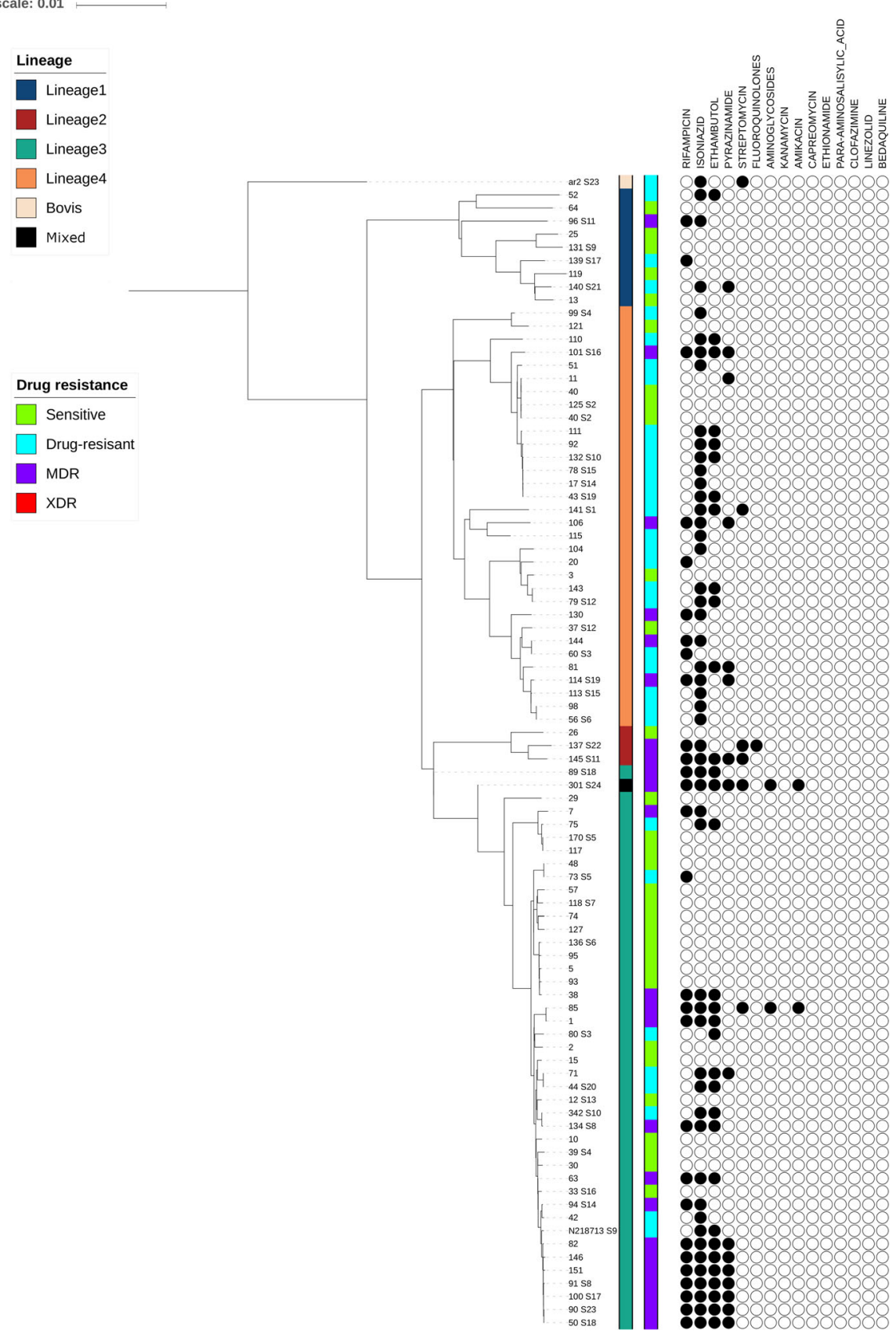

Fig. 1 Phylogenetic tree showing relationship of M. tuberculosis drug resistance strains, and pattern of drug resistance

the PZA resistance isolates. Such isolates also possessed mutations either in drug resistance genes for RIF or INH. INH, FQS and SLIDs are used for shorter MDR-TB treatment regimes. However, mutations involving genes associated with INH, EMB, FQs and SLIDs resistance affect the selection of appropriate treatment regimens $[15,19]$. INH and EMB have been in use for several decades either as part of the standard treatment regimen for drug susceptible TB and INH monotherapy as infection preventive therapy for HIV infected individuals [40]. On the other hand, MTBC isolates from DS-TB participants had no mutations in genes encoding for INH, RIF, PZA, SM and EMB, which is in keeping with Cryptic consortium findings that reported susceptibility profiles for all isolates unless uncharacterized mutations or missing key nucleotide calls were present [41]. We found 2 pre-XDR-TB patients possessing $\mathrm{R} 446 \mathrm{C}$ and $\mathrm{C} 517 \mathrm{Tmutations}$ in the $\mathrm{gyrB}$ and rrs genes, in addition S315T, S450L, G406A and C517T mutations in the $k a t G, r p o B, e m b B$ and rrs genes respectively. At this juncture, it is worthwhile to translate these 
Table 5 Description of lineages, spoligotype, cluster of drug resistance M. tuberculosis and genotype at important drug loci

\begin{tabular}{|c|c|c|c|c|c|c|c|c|c|c|c|c|c|}
\hline \multirow{3}{*}{$\begin{array}{l}\text { Isolate } \\
\text { ID }\end{array}$} & \multirow[t]{3}{*}{ Lineages } & \multirow[t]{3}{*}{ Spoligotype } & \multirow{3}{*}{$\begin{array}{l}\text { WGS } \\
\text { cluster }\end{array}$} & \multicolumn{10}{|c|}{ Genotype at drug loci } \\
\hline & & & & \multirow{2}{*}{$\begin{array}{l}\text { RIF } \\
r p o B\end{array}$} & \multirow{2}{*}{$\begin{array}{l}\mathrm{ZN} \\
\text { katG }\end{array}$} & \multirow{2}{*}{$\begin{array}{l}\text { AMK } \\
\text { rrs }\end{array}$} & \multirow{2}{*}{$\begin{array}{l}\text { PZ } \\
\text { pncA }\end{array}$} & \multirow{2}{*}{$\begin{array}{l}\text { FLR } \\
\text { gyrB }\end{array}$} & \multirow{2}{*}{$\begin{array}{l}\text { AMG } \\
\text { rrs }\end{array}$} & \multicolumn{2}{|l|}{ EMB } & \multicolumn{2}{|l|}{ ST } \\
\hline & & & & & & & & & & $e m b B$ & $\begin{array}{l}\text { embC- } \\
\text { embA }\end{array}$ & rpsL_ & rrs \\
\hline 1 & lineage3 & CAS & MDR & S450L & S315T & & $\begin{array}{l}\text { Large deletion } \\
\text { pncA Rv2044c }\end{array}$ & & & & & & \\
\hline 7 & lineage3 & CAS & MDR & S450L & S315T & & & & & & & & \\
\hline 11 & lineage4 & LAM & DR & & & & D8N & & & & & & \\
\hline 20 & lineage4 & LAM & DR & D435Y & & & & & & & & & \\
\hline 38 & lineage3 & CAS & MDR & S450L & N138S & & & & & $\begin{array}{l}\text { M306V, } \\
\text { Q497R, } \\
\text { G406A }\end{array}$ & & & \\
\hline 42 & lineage3 & CAS & DR & & S315T & & & & & & & & \\
\hline 51 & lineage4 & LAM & DR & & S315T & & & & & & & & \\
\hline 52 & lineage1 & EAl & DR & & S315T & & & & & Y319C & & & \\
\hline 63 & lineage3 & CAS & MDR & S450L & S315T & & & & & M306I & & & \\
\hline 71 & lineage3 & CAS & DR & & S315T & & G17D & & & Q497R & & & \\
\hline 75 & lineage3 & CAS & $\mathrm{DR}$ & & S315T & & & & & G406D & & & \\
\hline 81 & lineage4 & LAM & DR & & S315T & & L85P & & & $\begin{array}{l}\text { G406S, } \\
\text { M306I }\end{array}$ & & & \\
\hline 82 & lineage3 & CAS & MDR & S450L & S315T & & V128G & & & M306L & & & \\
\hline 85 & lineage3 & CAS & MDR & S450L & S315T & C517T & & & C517T & G406A & & & C517T \\
\hline 92 & lineage4 & LAM & $\mathrm{DR}$ & & S315T & & & & & $\begin{array}{l}\text { Q497R, } \\
\text { G406S }\end{array}$ & & & \\
\hline 98 & lineage4 & LAM & DR & & S315T & & & & & & & & \\
\hline 104 & lineage4 & LAM & DR & & S315T & & & & & & & & \\
\hline 106 & lineage4 & LAM & MDR & S450L & S315T & & Q10R & & & & & & \\
\hline 110 & lineage4 & LAM & $\mathrm{DR}$ & & S315T & & & & & & & & \\
\hline 111 & lineage4 & LAM & DR & & S315T & & & & & & & & \\
\hline 115 & lineage4 & LAM & $\mathrm{DR}$ & & S315T, S302R & & & & & & & & \\
\hline 130 & $\begin{array}{l}\text { lineage } \\
4\end{array}$ & LAM & MDR & S450L & S315T & & & & & & & & \\
\hline 143 & $\begin{array}{l}\text { lineage } \\
4\end{array}$ & LAM & $\mathrm{DR}$ & & S315T & & & & & & $\mathrm{C} 16 \mathrm{~T}$ & & \\
\hline 144 & $\begin{array}{l}\text { lineage } \\
4\end{array}$ & CAS & MDR & S450L & S315T & & & & & & & & \\
\hline 146 & $\begin{array}{l}\text { lineage } \\
3\end{array}$ & CAS & MDR & S450L & S315T & & V128G & & & & & & \\
\hline 151 & $\begin{array}{l}\text { lineage } \\
3\end{array}$ & CAS & MDR & S450L & S315T & & V128G & & & Q497R & & & \\
\hline $\begin{array}{l}100- \\
\text { S17 }\end{array}$ & $\begin{array}{l}\text { lineage } \\
3\end{array}$ & CAS & MDR & S450L & S315T & & V128G & & & Q497R & & & \\
\hline $\begin{array}{l}101- \\
\text { S16 }\end{array}$ & $\begin{array}{l}\text { lineage } \\
4\end{array}$ & LAM & MDR & S450L & S315T, S302R & & D49G & & & Q497R & & & \\
\hline $\begin{array}{l}113- \\
\text { S15 }\end{array}$ & $\begin{array}{l}\text { lineage } \\
4\end{array}$ & LAM & DR & & S315T & & & & & & & & \\
\hline $\begin{array}{l}114- \\
\text { S19 }\end{array}$ & $\begin{array}{l}\text { lineage } \\
4\end{array}$ & LAM & MDR & S450L & S315T & & D63A & & & & & & \\
\hline $\begin{array}{l}132 \\
S 10\end{array}$ & $\begin{array}{l}\text { lineage } \\
4\end{array}$ & LAM & $\mathrm{DR}$ & & S315T & & & & & & & & \\
\hline 134 & lineage & CAS & MDR & S450L & S315T & & & & & G406S & & & \\
\hline
\end{tabular}


Table 5 Description of lineages, spoligotype, cluster of drug resistance M. tuberculosis and genotype at important drug loci (Continued)

\begin{tabular}{|c|c|c|c|c|c|c|c|c|c|c|c|c|}
\hline \multirow{3}{*}{$\begin{array}{l}\text { Isolate } \\
\text { ID }\end{array}$} & \multirow[t]{3}{*}{ Lineages } & \multirow[t]{3}{*}{ Spoligotype } & \multirow{3}{*}{$\begin{array}{l}\text { WGS } \\
\text { cluster }\end{array}$} & \multicolumn{9}{|c|}{ Genotype at drug loci } \\
\hline & & & & \multirow{2}{*}{$\begin{array}{l}\mathrm{RIF} \\
r p o B\end{array}$} & \multirow{2}{*}{$\begin{array}{l}\mathrm{ZN} \\
\text { katG }\end{array}$} & \multirow{2}{*}{$\begin{array}{l}\text { AMK } \\
\text { rrs }\end{array}$} & \multirow{2}{*}{$\begin{array}{l}\mathrm{PZ} \\
\text { pncA }\end{array}$} & \multirow{2}{*}{$\begin{array}{l}\text { FLR } \\
\text { gyrB }\end{array}$} & \multirow{2}{*}{$\begin{array}{l}\text { AMG } \\
\text { rrs }\end{array}$} & \multicolumn{2}{|l|}{ EMB } & ST \\
\hline & & & & & & & & & & $\overline{e m b B}$ & $\begin{array}{l}e m b C- \\
e m b A\end{array}$ & $r p s L_{-} r r s$ \\
\hline S8 & 3 & & & & & & & & & & & \\
\hline $\begin{array}{l}137- \\
\text { S22 }\end{array}$ & lineage2 & Beijing & MDR & S450L & S315T & & & R446C & & & & \\
\hline $\begin{array}{l}139- \\
\text { S17 }\end{array}$ & $\begin{array}{l}\text { lineage } \\
1\end{array}$ & $\mathrm{EAl}$ & DR & & & & & & & & & \\
\hline $\begin{array}{l}140- \\
\text { S21 }\end{array}$ & lineage 1 & EAl & $\mathrm{DR}$ & & $\begin{array}{l}\text { OxyR-ahpC, C52T, } \\
\text { large deletion, S315T }\end{array}$ & & A193AT & & & & & \\
\hline $141-51$ & $\begin{array}{l}\text { lineage } \\
4\end{array}$ & LAM & DR & & S315T & & $\begin{array}{l}\text { Large, deletion, } \\
\text { pncA-Rv2044c }\end{array}$ & & & & & \\
\hline $\begin{array}{l}145- \\
\text { S11 }\end{array}$ & $\begin{array}{l}\text { lineage } \\
2\end{array}$ & Beijing & MDR & S450L & S315T & & P69L & & & $\begin{array}{l}\text { M306T, } \\
\text { G406A }\end{array}$ & & K43R \\
\hline $17-514$ & $\begin{array}{l}\text { lineage } \\
4\end{array}$ & LAM & $\mathrm{DR}$ & & S315T & & & & & & & \\
\hline $\begin{array}{l}301- \\
\text { S24 }\end{array}$ & $\begin{array}{l}\text { lineage } \\
3\end{array}$ & CAS & MDR & S450L & S315T & C517T & $\mathrm{A} 46 \mathrm{~V}$ & & C517T & $\begin{array}{l}\text { M306G, } \\
\text { G406S }\end{array}$ & & \\
\hline $\begin{array}{l}342- \\
\text { S10 }\end{array}$ & $\begin{array}{l}\text { lineage } \\
3\end{array}$ & CAS & DR & & S315T & & & & & G406S & & \\
\hline 43-S19 & lineage4 & LAM & $\mathrm{DR}$ & & S315T & & & & & & & \\
\hline $44-\$ 20$ & $\begin{array}{l}\text { lineage } \\
3\end{array}$ & CAS & $\mathrm{DR}$ & & S315T & & & & & & & \\
\hline 50-S18 & $\begin{array}{l}\text { lineage } \\
3\end{array}$ & CAS & MDR & S450L & S315T & & V128G & & & Y334H, & C16T & \\
\hline $56-56$ & $\begin{array}{l}\text { lineage } \\
4\end{array}$ & LAM & $\mathrm{DR}$ & & S315T & & & & & & & \\
\hline $60-\$ 3$ & $\begin{array}{l}\text { lineage } \\
4\end{array}$ & LAM & $\mathrm{DR}$ & S450L & & & & & & & & \\
\hline 73-\$5 & lineage3 & CAS & $\mathrm{DR}$ & S450L & & & & & & & & \\
\hline 78-S15 & lineage4 & LAM & $\mathrm{DR}$ & & S315T & & & & & & & \\
\hline 79-S12 & lineage4 & LAM & $\mathrm{DR}$ & & S315T & & & & & & C16T & \\
\hline $80-\$ 3$ & lineage3 & CAS & $\mathrm{DR}$ & & & & & & & M306I & C16T & \\
\hline 89-\$18 & lineage4 & LAM & MDR & S450L & S315T & & & & & & & \\
\hline $90-\$ 23$ & $\begin{array}{l}\text { lineage } \\
3\end{array}$ & CAS & MDR & S450L & S315T & & V128G & & & $\begin{array}{l}\text { Q497R, } \\
\text { M306V }\end{array}$ & & \\
\hline 91-S8 & $\begin{array}{l}\text { lineage } \\
3\end{array}$ & CAS & MDR & S450L & S315T & & V128G, & & & Q497R & & \\
\hline 94-S14 & $\begin{array}{l}\text { lineage } \\
3\end{array}$ & CAS & MDR & S450L & S315T & & & & & & & \\
\hline $96-S 11$ & lineage1 & EAl & MDR & S450L & S315T & & & & & & & \\
\hline 99-\$4 & $\begin{array}{l}\text { lineage } \\
4\end{array}$ & LAM & $\mathrm{DR}$ & & S315T & & & & & & & \\
\hline S23 & lineage & & DR & & S315T & & & & & & $\mathrm{C} 16 \mathrm{~T}$ & K43R \\
\hline S9 & $\begin{array}{l}\text { lineage } \\
3\end{array}$ & CAS & DR & & S315T & & & & & & & \\
\hline
\end{tabular}

RIF Rifampicin, INH Isoniazid, AMK Amikacin, PZ Pyrazinamide, FLR Fluoroquinolones, AMG Aminoglycosides, EMB Ethambutol, ST Streptomycin

mutations into clinical practice and investigate their association with participant's health outcomes. In this study, participants with MDR-TB were cured using the recommended treatment regimen and reverted late to culture negativity as compared to those with mono- or polyresistance (Table 4). Time to culture conversion was 
highly prolonged to more than 6 months in participants with pre-XDR-TB, who had multiple mutations. Delayed time to culture conversion in our study is similar to findings by Sangita et al., [42] and Shibabaw et al., [43] in India and Ethiopia who documented reversion time to culture negativity after 125 and 77 days of treatment respectively. In addition, the spectrum of mutations to genes that predict phenotypic resistance to anti-TB drugs determines treatment outcomes. Fortunately, 82.5\% (47/57) of study participants achieved treatment success, similar to findings by Meressa et al., [44] in Ethiopia. This success rate is $30 \%$ higher than the global MDR-TB treatment success rate [15], positioning the WGS method along with culture based DST as a useful testing algorithm for rigorous microbiological monitoring that will accelerate the 2035 strategic END-TB vision to create a world population free of TB [45]. Over $17 \%$ of study participants had unfavourable treatment outcomes (5\% mortality and $12 \%$ lost-to- follow-up), similar to that reported by Meressa et al. [44],. However, this is lower than that reported by Dheda et al., [46] and Milanov et al., [47] in South Africa and Bulgaria who both documented over $50 \%$ unfavourable treatment outcomes. Previous findings have argued that severe malnutrition $(\mathrm{BMI}<16 \mathrm{~kg} / \mathrm{m} 2)$, HIV coinfection, previous history of anti-TB therapy and drug adverse events can predict poor treatment outcomes [47, 48]. In this study, $29.9 \%$ of the study participants had low BMI and 23\% were infected with HIV but had no effects on MDR-TB treatment outcomes.

In our study, the phylogenetic analysis showed distinct DR-TB spoligotype lineages similar to a previous finding by Kidenya et al. [49] in North-western Tanzania who reported strain variation across different spoligotypedefined M. tuberculosis lineages. We found that, the Central Asian strains (CAS) genotype (lineage 3) were the predominant lineages (Table 5), with no evidence of any change in terms of the CAS dominance over the past few years in Tanzania [50]. The CAS is among the prevalent lineage in the Indian subcontinent, South-East Asia, the Middle-East and East-Africa [51], showing a North-South divide along the Tropic of Cancer in the Eastern hemisphere - mainly in Asia, and partly prolonged along the horn of Africa [51, 52]. The dominance of CAS lineages in our local settings might be attributed to early contact due to migration and trade between people in Asian and East Africa countries. The seemingly prolonged stable dominance of CAS lineage reflects limited movement in of new infections from other sources/origins to influence the constantly circulating strains.

The main strength of our study is that we have correlated and linked WGS with treatment response and outcomes in a resource limited clinical TB endemic setting like Tanzania, which was not available previously. WGS provides high resolution when investigating diseases transmission in outbreaks, provides results for 2nd line drugs which is currently not performed in our settings. In addition to that, the WGS enables earlier use of the most appropriate drug regimen, thus improving patient outcomes and reducing overall healthcare costs [33]. This is the first step to start thinking how this technology could be included and add value in the future DRTB diagnosis cascade, in high burden areas with limited resources where the need for rapid and accurate tools for assisting clinical decision making for optimal patient care and in predicting the treatment outcomes is very high.

However, our study has some limitations. Phenotypic culture-based DST for PZA, and cycloserine, which were part of the standardized treatment regimen for all participants was missing. In addition, concordance between line probe assays (LPA) genotype MDBTDRplus and MTBDRsl and WGS could not be done, which would have given a full comparison of the robustness of the WGS since the former had not been in use at the time of the study. In addition, WGS was performed retrospectively on clinical isolates, genetic data was not applied in the real time in the clinical setting, and hence no treatment regimen was modified to favour outcomes. Moreover, the use of WGS on frozen isolates of $M$. $t u$ berculosis does not allow us to make considerations and comparisons between Xpert ${ }^{\circ} \mathrm{MTB} /$ Rif assay, phenotypic DST and WGS. Finally, WGS provides rapid and comprehensive diagnosis of DR-TB and the WHO has recognized its great potential for rapidly diagnosing drugresistant TB in diverse clinical settings. However, there are challenges that need to be overcome prior to the implementation of whole-genome sequencing in resourcelimited countries. These include high cost of equipment, the requirement for technical training, the need for expert guidance on the clinical interpretation of WGS data as the kind of information provided from the previous typing methods, the lack of simple solutions to obtain genome sequencing information directly from sputum samples and how it can be accommodated into our preexisting diagnostic frameworks. Nevertheless, the useful information presented in this study outweighs these limitations and can be used to advocate for a policy change in the adoption of molecular TB diagnostic algorithms.

\section{Conclusion}

WGS uncovered mutations in genes that predict phenotypic resistance to anti-TB drugs, signifying its importance in informed decision making prior to anti tuberculosis therapy. Expectedly, WGS was robust in ruling out DR-TB especially in absence of detectable mutations, which was the case in drug susceptible $M$. tuberculosis clinical isolates. The WGS-based DST best 
correlated with culture conversion rates and treatment outcome, indicating its potential application in designing an optimally individualized treatment regimen for favourable treatment outcomes in TB endemic settings.

\section{Methods}

\section{Study settings}

This study was conducted at Kibong'oto Infectious diseases hospital (KIDH) in Siha District, Kilimanjaro region, Tanzania. KIDH is the national centre of excellence for clinical management of drug resistant TB in the country and has a bed capacity of 320 . The hospital provides TB services to more than 150 and 500 patients with drug resistant and susceptible TB per year, respectively. Recruitment and sputa collections from study participants were done at KIDH. Xpert ${ }^{\circ} \mathrm{MTB} /$ Rif assay, smear microscopy for acid-fast-bacilli (AFB) and isolation of MTBC on Lowenstein-Jensen (LJ) solid medium was performed at KIDH Mycobacteriology laboratory. MTBC isolates were transported to the Central Tuberculosis Reference Laboratory (CTRL) located at Muhimbili National Hospital (MNH) in Dar-es-salaam, Tanzania, for phenotypic susceptibility testing (DST) to first- and second-line anti-TB drugs like RIF, INH, EMB, $\mathrm{SM}$, ofloxacin (OFX) and Kanamycin/Amikacin (KAN/ AMK) and DNA extraction. Due to its complexity, PZADST is not routinely performed in Tanzania. MTBC DNA were shipped to London School of Hygiene and Tropical Medicine (LSHTM) for WGS and bioinformatics analysis.

\section{Study design, population and recruitment of participants} This study involved 57 and 30 participants who harboured $M$. tuberculosis that were resistant and susceptible to anti-TB drugs respectively, presenting at KIDH during the study period in 2014. Participants with resistant isolates were recruited if they had laboratory results by either GeneXpert MTB/RIF or phenotypic culture and DST [16]. The drug resistance was either mono/ polyresistance-resistant or MDR-TB. The rest were recruited if they were infected with MTB that was susceptible to RIF by $\mathrm{Xpert}^{\circ} \mathrm{MTB} /$ Rif assay. Eligibility included age $\geq 18$ years, and willingness to sign a written informed consent and provide sputum samples for laboratory analysis. Very sick participants were excluded from the study.

\section{Data collection}

A standardized semi-structured questionnaire containing a set of study variables was used to collect data from study participants and medical charts were used to monitor treatment. Pre-treatment data that was collected included clinical information such as symptoms and signs suggestive of pulmonary tuberculosis (PTB), any previous history of TB treatment, HIV status, absolute $\mathrm{CD} 4+\mathrm{T}$ cell count, the body mass index as the ratio of weight $(\mathrm{kg})$ and (height) $)^{2}\left(\mathrm{~m}^{2}\right)$ and socio-demographic characteristics such as age and gender. MDR-TB was treated for at least 20 months and monitored monthly with culture and smear microscopy for AFB while DS TB was monitored with smear microscopy only to determine microbiological treatment response and programmatic outcomes. WGS was performed on baseline MTBC isolates.

\section{Laboratory procedures \\ Samples collection, culture of MTBC and phenotypic drug- susceptibility testing}

Each study participant provided approximately $4 \mathrm{~mL}$ of one spot sputum samples for culture. The samples were processed using the modified Petroff's method [31]. Briefly, $4 \mathrm{mLs}$ of sputum was added to $4 \mathrm{mLs}$ of $4 \%$ sodium hydroxide $(\mathrm{NaOH})$. The mixture was vortexed and left to stand at room temperature for $15 \mathrm{~min}$. Thereafter, the volume of the mixture was adjusted to $50 \mathrm{mLs}$ in a falcon tube and concentrated by centrifugation at $3000 \mathrm{~g}$ for $15 \mathrm{~min}$. Supernatants were discarded into a container with 25\% phenol. Sediments were suspended in Phosphate buffer saline solution (PBS) before being inoculated on LJ culture media as recommended by the Clinical and Laboratory Standard Institute (CLSI) for TB culture [22]. In summary, $200 \mu \mathrm{L}$ of sputum sediments were inoculated on two slopes of LJ medium containing either pyruvate or glycerol. Culture and identification of MTBC colonies were performed according to locally existing and CLSI standard operating procedures. Phenotypic drug susceptibility testing of the MTBC isolates was performed using a standard proportion method on LJ media $[53,54]$.

\section{DNA extraction and whole genome sequencing}

Genomic DNA was extracted at Muhimbili University of Health and Allied Sciences (MUHAS) using a modified protocol based on Restriction Fragment Length Polymorphism (RFLP) developed at the National Institute for Public Health and the Environment (RIVM), Bilthoven, Netherlands [55]. The concentration and quality of the DNA were measured using Qubit ${ }^{\mathrm{tm}} 4$. Fluorometer (Invitrogen $\left.{ }^{\circ}\right)$. DNA samples were shipped to London School of Hygiene and Tropical Medicine (LSHTM), United Kingdom for whole genome sequencing. The DNA were shipped in screw capped cryo-vials and sealed with parafilm materials. During shipment the DNA were packed in double box and transported in iced packed with insulators materials in a thermo-stable shipping box where the Styrofoam was at least $1.5 \mathrm{in}$. thick. Library preparation, cluster amplification and sequencing were performed according to the manufacturer's instructions 
(QIAGEN). The QIAseq FX DNA Library Kit (QIAGEN) was used for library preparation according to the manufacturer's protocol. The QIAseq FX DNA Library Kit covers DNA fragmentation for $15 \mathrm{~min}$, adapter ligation and a final purification of the samples using AMPure XP beads (Beckman-Coulter). Library DNA content was analysed using a Qubit 3.0 fluorometer. The sizes of DNA fragments were quantified using the Agilent High Sensitivity DNA Kit (Agilent Technologies) on an Agilent 2100 Bioanalyser (Agilent Genomics) according to the manufacturer's protocol. Samples were pooled to create pools of libraries at a concentration between 10 and $12 \mathrm{pM}$, and loaded into the $\mathrm{MiSeq}^{\circ}$ using $\mathrm{MiSeq}^{\circ}$ v2 Reagent Kit. WGS was performed at the LSHTM using MiseqTM Sequencing 172 System MiSeqV2-500 cycles (Illumina), producing paired-end sequence reads of 151 bp.

\section{Bioinformatics and genomic data analysis Quality control and mapping of reads}

Initial quality control $(\mathrm{QC})$ reads were characterized using Kraken version v1.1 to exclude contamination and low-quality reads bases of less than 20 Qscore (defined as $-10 \log 10(\mathrm{P})$, where $\mathrm{P}$ is the probability of an error as determined by the sequencing platform). Quality reads were mapped to the $\mathrm{H} 37 \mathrm{Rv}$ reference genome (AL123456) using BWA mem [56] with default settings. The median depth and the percentage of the reference covered by a minimum of 10 reads were calculated using SAMtools depth [56] and custom scripts. Samples with sufficient amounts of MTBC data were used for downstream analysis.

\section{Variant calling and in-silico resistance and lineage typing}

Variants in drug resistance gene candidates were called using LoFreq version v2.1.2 [57]. These were annotated and compared to the TBProfiler database [58] (http:// tbdr.lshtm.ac.uk/) as it does not perform its own variant calling but annotates existing calls as drug resistance mutations using a database of mutations. Additionally, large indels were identified by looking at depth in candidate genes. The coverage across lineage specific markers was inspected using htsbox (https://github.com/lh3/ htsbox) and custom scripts to assign specific lineages to the isolates.

\section{Phylogeny reconstruction}

Variants throughout the whole genome were called using SAMtools/BCFtools version v1.9 [59]. The resulting variant call format (VCF) files were collated together filtering was performed. In short, sites in samples were marked as missing if less than 5 reads aligned to a position and monomorphic sites or those with greater than $10 \%$ missing data were removed. Using all SNPs, a maximum likelihood phylogeny was constructed using ExaML version v3.0.21, a state of the art tool for phylogenomic analyses [60]. The phylogenetic reconstruction was used in conjunction with lineage predictions output by TBProfiler. These predictions were based on the universally adopted lineage nomenclature and SNP barcode reported by Coll et al. [61]. This was visualized with drug resistance phenotypes and lineages using iTOL [62]. The lineages were assigned based on the SNP barcode available at doi:https://doi.org/10.1038/ ncomms5812 and has been adopted as the standard for Mtb WGS data.

\section{Analysis of clinical data}

Descriptive statistics was performed for demographic characteristics, frequency and distribution of mutation patterns in MDR-TB and other resistance patterns in MTBC. A Pearson chi-square test was used to determine the association between age, gender, HIV status and CD4 counts if applicable, Body mass index (BMI), history of previous TB treatment and genotype drug resistance as the main outcome using STATA version 14 (StataCorp LP, College Station, TX, USA). A $p$-value of $<0.05$ considered statistically significant. Genotype drug resistance was defined as any mutations that are known to confer decreased anti tuberculosis drug susceptibility. Skewed data, Student's -test and Wilcoxon rank-sum tests were used for normally distributed data. The body weight based on BMI values for both adults was categorized into two groups namely; thinness $(\leq 18.5)$ and normal> 18.5 as recommended by the World Health Organization (WHO). Kappa statistics (K) were used to determine agreement between drug susceptibility testing (DST) and genetic drug resistance using four levels of agreement for kappa: <0.40 (poor), 0.40-0.59 (fair), $0.60-0.80$ (good), and $>0.80$ (excellent) [63].

\section{Abbreviations \\ AIDS: Acquired immunodeficiency syndrome; BMI: Body mass index; DR- TB: Drug resistant tuberculosis; DS-TB: drug susceptible tuberculosis; HIV: Human immunodeficiency virus; KIDH: Kibong'oto infectious diseases hospital; LJ: Lowenstein jensen; MDR-TB: Multidrug resistant Tuberculosis; MTB: Mycobacterium tuberculosis; PTB: Pulmonary tuberculosis; SNP: Single nucleotide polymorphism; TB: Tuberculosis; WHO: World health organization; XDR-TB: Extensive DR-TB}

\section{Acknowledgments}

We acknowledge laboratory staff of the Central Referral Tuberculosis Laboratory, Biochemistry Department at Muhimbili University of Health and Allied Science and the Director of Kibong'oto hospital for their logistic support during the execution of this study.

\section{Authors' contributions}

BZK and PMM conceived the idea, designed the study, developed data collection tool, acquired, analyzed and interpreted data, drafted and revised the manuscript. NAL participated in data collection and performed initial laboratory work; SC performed the laboratory work; JDK, MM, EVM, SEM MMR, SM and HMD contributed to conceptual, commented the manuscript and critically reviewed it; JEP analyzed and interpreted data, under the supervision of TGC and SC, and revised the manuscript; TGC and SC 
supervised the laboratory work and reviewed the manuscript; MIM conceived the idea, designed the review, interpreted data into metanarratives, reviewed the manuscript and supervised the entire process All authors read and approved the final version of this review before submission.

\section{Funding}

The study was funded by the Wellcome Trust Grant [WT087546MA] and the United Republic of Tanzania through the Ministry of Health, Community Development, Gender, Elderly and Children for funding this study. PMM was supported by the DELTAS Africa Initiative [Afrique One-ASPIRE /DEL-15-008]. Afrique One-ASPIRE is funded by a consortium of donors including the African Academy of Sciences (AAS), Alliance for Accelerating Excellence in Science in Africa (AESA), the New Partnership for Africa's Development Planning and Coordinating (NEPAD) Agency, the Wellcome Trust [107753/A/15/Z], and the UK government. PMM was also supported by the EDCTP 2 programme Senior Fellowship project for Dr. Stellah Mpagama (TMA 2016-1463). TGC is supported by the Medical Research Council UK (Grant no.MR/K000551/1, MR/ M01360X/1, MR/N010469/1, MR/R020973/1) and BBSRC (BB/R013063/1). SC is funded by the Medical Research Council UK (Grant no. MR/M01360X/1) and BBSRC (BB/R013063/1). The funders had no part in study design, data collection and interpretation, or the decision to submit the work for publication.

\section{Availability of data and materials}

Raw sequence data are available from the European Nucleotide Archive (ENA) under the project accession number PRJEB29435 (https://www.ebi.ac. uk/ena/data/view/PRJEB29435).

\section{Ethics approval and consent to participate}

The Senate Research and Publications Committee of the Muhimbili University of Health and Allied Sciences (MUHAS) in Tanzania approved the study (Ref. No. MU/PGS/PhD/Nol.VI/154). Permission to conduct the study was obtained from KIDH administration. Prior to any study procedure, we obtained written informed consent that was signed by all patients. All study participants received MDR-TB treatment according to existing National and global MDR-TB treatment guidelines in Tanzania [23, 27].

\section{Consent for publication}

Not applicable.

\section{Competing interests}

The authors declare that they have no competing interest related to this article.

\section{Author details}

'Department of Microbiology and Immunology, School of Medicine, Muhimbili University of Health and Allied Sciences (MUHAS), Dar es Salaam, Tanzania. ${ }^{2}$ Tanzania Wildlife Research Institute (TAWIRI), Arusha, Tanzania. ${ }^{3}$ Kibong'oto Infectious Disease Hospital (KIDH), Sanya Juu, Tanzania. ${ }^{4}$ Department of Global Health and Biomedical Sciences, School of Life Sciences and Bioengineering, Nelson Mandela African Institution of Science and Technology (NM-AIST), Arusha, Tanzania. ${ }^{5}$ Field Epidemiology and Laboratory Training Programme, Dar es Salaam, Tanzania. ${ }^{6}$ Faculty of Infectious and Tropical Diseases, London School of Hygiene \&Tropical Medicine (LSHTM), Keppel Street, London WC1E 7HT, UK. ${ }^{7}$ Department of Medical Microbiology, Catholic University of Health and Allied Sciences, Mwanza, Tanzania. ${ }^{8}$ Southern African Centre for Infectious Diseases Surveillance (SACIDS), Sokoine University of Agriculture (SUA), Morogoro, Tanzania. ${ }^{9}$ Department of Biochemistry, Muhimbili University of Health and Allied Sciences (MUHAS), Dar es Salaam, Tanzania. ${ }^{10}$ Faculty of Epidemiology and Population Health, London School of Hygiene \&Tropical Medicine (LSHTM), Keppel Street, London WC1E 7HT, UK.

Received: 4 July 2019 Accepted: 12 February 2020

Published online: 21 February 2020

\section{References}

1. Raviglione M, Sulis G. Tuberculosis 2015: burden, challenges and strategy for control and elimination. Infectious disease reports. 2016;8:6570.

2. W.H.O. Global Tuberculosis Report 2017. World Health Organization 2017.
3. Narasimhan, P., Wood, J., Maclntyre, C. R \& Mathai, D. 2013. Risk Factors for Tuberculosis. Pulm Med V 2013, Article ID 828939, 11 pages. http://dx.doi. org/https://doi.org/10.1155/2013/828939

4. Kharsany ABM, Karim QA. HIV infection and AIDS in sub-Saharan Africa: current status, challenges and opportunities. Open AIDS J. 2016;10:34-48.

5. W.H.O. World Tuberculosis DAY 2019. https://www.afro.who.int/mediacentre/events/world-tuberculosis-day-2019.

6. Albert $H$, Nathavitharana RR, Isaacs C, Pai M, Denkinger CM, Boehme CC, C. C. Development, roll-out and impact of Xpert MTB/RIF for tuberculosis: what lessons have we learnt and how can we do better? Eur Respir J. 2016;48(2):516-25.

7. Musa, B.M., Adamu A.L., Galadanci, N.A., Zubayr, B., Odoh, C.N., Aliyu, M.H. 2017. Trends in prevalence of multi drug resistant tuberculosis in subSaharan Africa: A systematic review and meta-analysis. PLoS One 12(9): e0185105. https://doi.org/https://doi.org/10.1371/journal.pone.0185105.

8. Dye, C., Harries, A.D., Maher, D., Mehran Hosseini, S., Nkhoma, W \& Salaniponi, F.M. 2006. Disease and mortality in sub-Saharan Africa. 2nd edition. In Jamison DT, Feachem RG, Makgoba MW, Bos, E.R., Baingana, F.K., Hofman, K. J \& Rogo, K.O. Washington (DC): the International Bank for Reconstruction and Development / the World Bank; 2006. ISBN-10: 0-82136397-2, ISBN-13: 978-0-8213-6397-3.

9. Espinal MA, Laszlo A, Simonsen L, Boulahbal F, Kim SJ, Reniero A, Hoffner S, Rieder HL, Binkin N, Dye C, Williams R, Raviglione MC. Global trends in resistance to anti-TB drugs. N Engl J Med. 2001;344:1294-303.

10. Chonde TM, Basra D, Mfinanga SGM, Range N, Lwilla F, Shirima RP, van Deun A, Zignol M, Cobelens FG, Egwaga SM, van Leth F. National antituberculosis drug resistance study in Tanzania. IJTLD. 2010;14(8):967-972(6).

11. Glynn JR. Resurgence of tuberculosis and the impact of HIV infection. $\mathrm{Br}$ Med Bull. 1998;54:579-93.

12. W.H.O. Companion handbook to the WHO guidelines for the programmatic management of drug-resistant tuberculosis. Geneva: World Health Organization; 2014.

13. Foongladda S, Banu S, Pholwat S, Gratz J, O-Thong S, Nakkerd N, Chinli R, Ferdous SS, Rahman SMM, Rahman A, Ahmed S, Heysell S, Sariko M, Kibiki G, Houpt E. Comparison of TaqMan ${ }^{\circledR}$ Array card and MYCOTBTM with conventional phenotypic susceptibility testing in MDR-TB. Int J Tuberc Lung Dis. 2016;20:1105-12.

14. Chonde TM, Basra D, Mfinanga SG, et al. National anti-tuberculosis drug resistance study in Tanzania. Int J Tuberc Lung Dis. 2010;14(8):967-72.

15. W.H.O. WHO treatment guidelines for drug- resistant tuberculosis 2016. Geneva; 2016.

16. Mbelele PM, Aboud S, Mpagama SG, Matee MI. Improved performance of Xpert MTB/RIF assay on sputum sediment samples obtained from presumptive pulmonary tuberculosis cases at Kibong'oto infectious diseases hospital inÂ Tanzania. BMC Infect Dis. 2017;17:808.

17. Karimi H, En-Nanai L, Oudghiri A, Chaoui I, Laglaoui A, Bourkadi JE, El Mzibri M, Abid M. Performance of GenoType ${ }^{\oplus}$ MTBDRplus assay in the diagnosis of drug-resistant tuberculosis in Tangier, Morocco. J Glob Antimicrob Resist. 2017;12:63-7.

18. Theron G, Peter J, Richardson M, Warren R, Dheda K, Steingart KR. GenoType ${ }^{\oplus}$ MTBDRsl assay for resistance to second-line anti-tuberculosis drugs. The Cochrane database of systematic reviews. 2016;9:CD010705.

19. Sotgiu G, Tiberi S, Centis R, D'Ambrosio L, Fuentes Z, Zumla A, Migliori GB. Applicability of the shorter \&\#x2018;Bangladesh regimen\&\#x2019; in high multidrug-resistant tuberculosis settings. Int J Infect Dis. 2017;56:190-3.

20. Feliciano CS, Namburete El, Plaça JR, K. Peronni, Dippenaar A, Warren RM, Silva WAJ, Bollela VR. Accuracy of whole genome sequencing versus phenotypic (MGIT) and commercial molecular tests for detection of drugresistant mycobacterium tuberculosis isolated from patients in Brazil and Mozambique. Tuberculosis. 2018;110:59-67.

21. Chatterjee A, Nilgiriwala K, Saranath D, Rodrigues C, Mistry N. Whole genome sequencing of clinical strains of mycobacterium tuberculosis from Mumbai, India: A potential tool for determining drug-resistance and strain lineage. Tuberculosis. 2017;107:63-72.

22. Quan TP, Bawa Z, Foster D, Walker T, Elias CDO, Rathod P, M. M. M. I. Group, labal Z, Bradley P, Mowbray J, Walker AS, Crook DW, Wyllie DH, Peto TEA, Smith EG. Evaluation of whole-genome sequencing for mycobacterial species identification and drug susceptibility testing in a clinical setting: a large-scale prospective assessment of performance against line probe assays and Phenotyping. J Clin Microbiol. 2018:56:e01480-17.

23. Shea J, Halse TA, Lapierre P, Shudt M, Kohlerschmidt D, Van Roey P, Limberger R, Taylor J, Escuyer V, Musser KA. Comprehensive whole-genome 
sequencing and reporting of drug resistance profiles on clinical cases of mycobacterium tuberculosis in New York state. J Clin Microbiol. 2017; 55:1871-82.

24. Walker, T. M., T. A. Kohl, S. V. Omar, J. Hedge, C. Del Ojo Elias, P. Bradley, Z. Iqbal, S. Feuerriegel, K. E. Niehaus, D. J. Wilson, D. A. Clifton, G. Kapatai, C. L. C. Ip, R. Bowden, F. A. Drobniewski, C. Allix-BÃ@guec, C. Gaudin, J. Parkhill, R. Diel, P. Supply, D. W. Crook, E. G. Smith, A. S. Walker, N. Ismail, S. Niemann, T. E. A. Peto, and G. Modernizing Medical Microbiology Informatics. 2015. Whole-genome sequencing for prediction of mycobacterium tuberculosis drug susceptibility and resistance: a retrospective cohort study. Lancet Infect Dis 15:1193-1202.

25. Pang Y, Dong H, Tan Y, Deng Y, Cai X, Jing H, Xia H, Li Q, Ou X, Su B, Li X, Zhang Z, Li J, Zhang J, Huan S, Zhao Y. Rapid diagnosis of MDR and XDR tuberculosis with the MeltPro TB assay in China. Sci Rep. 2016;6:25330.

26. Shah MA, Shah I. Increasing prevalence of pediatric drug-resistant tuberculosis in Mumbai, India, and its outcome. Pediatr Infect Dis J. 2018;37:1261-3

27. Chen J, Peng P, Du Y, Ren Y, Chen L, Rao Y, Wang W. Early detection of multidrug- and pre-extensively drug-resistant tuberculosis from smearpositive sputum by direct sequencing. BMC Infect Dis. 2017;17:300.

28. Miotto P, Tessema B, Tagliani E, Chindelevitch L, Starks AM, Emerson C, Hanna D, Kim PS, Liwski R, Zignol M, Gilpin C, Niemann S, Denkinger CM, Fleming J, Warren RM, Crook D, Posey J, Gagneux S, Hoffner S, Rodrigues C, Comas IA, Engelthaler DM, Murray M, Alland D, Rigouts L, Lange C, Dheda K, Hasan R, Ranganathan UDK, McNerney R, Ezewudo M, Cirillo DM, Schito $M, K$ Ãser CU, Rodwell TC. A standardised method for interpreting the association between mutations and phenotypic drug resistance in mycobacterium tuberculosis. Eur Respir J. 2017;50:1701354.

29. Mbelele P, Mohamed S, Sauli E, Mpolya E, Mfinanga S, Addo K, Heysell S, Mpagama S. Meta-narrative review of molecular methods for diagnosis and monitoring of multidrug-resistant tuberculosis treatment in adults. International Journal of Mycobacteriology. 2018;7:299-309.

30. Papaventsis D, Casali N, Kontsevaya I, Drobniewski F, Cirillo DM, Nikolayevskyy V. Whole genome sequencing of Mycobacterium tuberculosis for detection of drug resistance: a systematic review. Clin Microbiol Infect. 2017;23:61-8

31. Witney AA, Gould KA, Arnold A, Coleman D, Delgado R, Dhillon J, Pond MJ, Pope CF, Planche TD, Stoker NG, Cosgrove CA, Butcher PD, Harrison TS, Hinds J. Clinical application of whole-genome sequencing to inform treatment for multidrug-resistant tuberculosis cases. J Clin Microbiol. 2015;53:1473-83.

32. McNerney R, Clark TG, Campino S, Rodrigues C, Dolinger D, Smith L, Cabibbe AM, Dheda K, Schito M. Removing the bottleneck in whole genome sequencing of mycobacterium tuberculosis for rapid drug resistance analysis: a call to action. Int J Infect Dis. 2017;56:130-5.

33. Witney AA, Cosgrove CA, Arnold A, Hinds J, Stoker NG, Butcher PD. Clinical use of whole genome sequencing for mycobacterium tuberculosis. BMC Med. 2016;14:46.

34. Rapid Communication WHO. Key changes to treatment of multidrug- and rifampicin-resistant tuberculosis. Geneva: World Health Organisation; 2018.

35. Phelan J, Coll F, McNerney R, Ascher DB, Pires DEV, Furnham N, Coeck N, Hill-Cawthorne GA, Nair MB, Mallard K, Ramsay A, Campino S, Hibberd ML, Pain A, Rigouts L, Clark TG. Mycobacterium tuberculosis whole genome sequencing and protein structure modelling provides insights into antituberculosis drug resistance. BMC Med. 2016;14:31.

36. Ssengooba W, Meehan CJ, Lukoye D, Kasule GW, Musisi K, Joloba ML, Cobelens FG, de Jong BC. Whole genome sequencing to complement tuberculosis drug resistance surveys in Uganda. Infect, Genet Evol : J Molecular epidemiology and evolutionary genetics in infectious diseases. 2016;40:8-16.

37. Fonseca JD, Knight GM, McHugh TD. The complex evolution of antibiotic resistance in $<$ em $>$ mycobacterium tuberculosis $</$ em $>$. Int J Infect Dis. 2015;32:94-100.

38. Nguyen L. Antibiotic resistance mechanisms in M. tuberculosis: an update. Arch Toxicol. 2016;90:1585-604.

39. Dookie N, Rambaran S, Padayatchi N, Mahomed S, Naidoo K. Evolution of drug resistance in mycobacterium tuberculosis: a review on the molecular determinants of resistance and implications for personalized care. J Antimicrob Chemother. 2018;73:1138-51.

40. Ayele HT, van Mourik MS, Debray TP, Bonten MJ. Isoniazid prophylactic therapy for the prevention of tuberculosis in HIV infected adults: A systematic review and meta-analysis of randomized trials. PLoS One. 2015; 10:e0142290.

41. CRyPTIC Consortium and the 100,000 Genomes Project, Allix-Béguec C, Arandjelovic I, et al. Prediction of Susceptibility to First-Line Tuberculosis Drugs by DNA Sequencing. N Engl J Med. 2018;379(15):1403-15. https://doi. org/10.1056/NEJMoa1800474.

42. Patel SV, Nimavat KB, Patel AB, Mehta KG, Shringarpure K, Shukla LK. Sputum smear and culture conversion in multidrug resistance tuberculosis patients in seven districts of Central Gujarat, India: A longitudinal study. Indian J Commun Med : Official Publication Indian Assoc Prev Soc Med. 2018;43:117-9.

43. Shibabaw A, Gelaw B, Wang S-H, Tessema B. Time to sputum smear and culture conversions in multidrug resistant tuberculosis at University of Gondar Hospital, Northwest Ethiopia. PLoS One. 2018;13:e0198080.

44. Meressa D, Hurtado RM, Andrews JR, Diro E, Abato K, Daniel T, Prasad P, Prasad R, Fekade B, Tedla Y, Yusuf H, Tadesse M, Tefera D, Ashenafi A, Desta G, Aderaye G, Olson K, Thim S, Goldfeld AE. Achieving high treatment success for multidrug-resistant TB in Africa: initiation and scale-up of MDR TB care in Ethiopiaâ€ an observational cohort study. Thorax. 2015;70:1181-8.

45. W.H.O. The END TB Strategy 2015-2035 [Internet]. Geneva: World Health Organization; 2015. Available from:http://www.who.int/tb/End_TB_brochure. pdf:

46. Dheda K, Limberis JD, Pietersen E, Phelan J, Esmail A, Lesosky M, Fennelly KP, te Riele J, Mastrapa B, Streicher EM, Dolby T, Abdallah AM, Ben-Rached F, Simpson J, Smith L, Gumbo T, van Helden P, Sirgel FA, McNerney R, Theron G, Pain A, Clark TG, Warren RM. Outcomes, infectiousness, and transmission dynamics of patients with extensively drug-resistant tuberculosis and home-discharged patients with programmatically incurable tuberculosis: a prospective cohort study. Lancet Respir Med. 2017:5:269-81.

47. Milanov V, Falzon D, Zamfirova M, Varleva T, Bachiyska E, Koleva A, Dara M. Factors associated with treatment success and death in cases with multidrug-resistant tuberculosis in Bulgaria, 2009-2010. Int J Mycobacteriol. 2015:4:131-7.

48. Umanah T, Ncayiyana J, Padanilam $X$, Nyasulu PS. Treatment outcomes in multidrug resistant tuberculosis-human immunodeficiency virus co-infected patients on anti-retroviral therapy at Sizwe tropical disease hospital Johannesburg, South Africa. BMC Infect Dis. 2015;15:478.

49. Kidenya BR, Mshana SE, Fitzgerald DW, Ocheretina O. Genotypic drug resistance using whole-genome sequencing of mycobacterium tuberculosis clinical isolates from North-Western Tanzania. Tuberculosis. 2018;109:97-101.

50. World Health Organization. WHO treatment guidelines for drug-resistant tuberculosis. 2016 update WHO/HTM/TB/2016.04. Geneva: World Health Organization; 2016. Available from: www.who.int/tb/MDRTBguidelines2016.pdf.

51. Belay M, Ameni G, Bjune G, Couvin D, Rastogi N, Abebe F. Strain diversity of mycobacterium tuberculosis isolates from pulmonary tuberculosis patients in Afar pastoral region of Ethiopia. Biomed Res Int. 2014;2014:238532.

52. Mbugi EV, Katale BZ, Streicher EM, Keyyu JD, Kendall SL, Dockrell HM, Michel $\mathrm{AL}$, Rweyemamu MM, Warren RM, Matee MI, van Helden PD, Couvin D, Rastogi N. Mapping of mycobacterium tuberculosis complex genetic diversity profiles in Tanzania and other African countries. PLoS One. 2016;11: e0154571.

53. Matee M, Mtei L, Lounasvaara T, Wieland-Alter W, Waddell R, Lyimo J, Bakari M, Pallangyo K, von Reyn CF. Sputum microscopy for the diagnosis of HIVassociated pulmonary tuberculosis in Tanzania. BMC Public Health. 2008;8:68.

54. Yurtsever SG, Bicmen C, Gündüz AT, Ozkutuk N, Salman S, Demirci M. Comparison of proportion method in Löwenstein-Jensen medium with the BACTEC 460 TB system for antimycobacterial susceptibility testing of Mycobacterium tuberculosis isolates. Microbiol Bulletin. 2011;45:623-31.

55. van Soolingen D, Hermans PW, de Haas PE, Soll DR, van Embden JD. Occurrence and stability of insertion sequences in mycobacterium tuberculosis complex strains: evaluation of an insertion sequencedependent DNA polymorphism as a tool in the epidemiology of tuberculosis. J Clin Microbiol. 1991;29:2578-86.

56. Li, H. 2013. Aligning sequence reads, clone sequences and assembly contigs with BWA-MEM. Quantitative biology > genomics (submitted on 16 mar 2013 (v1), last revised 26 may 2013 (this version, v2).

57. Wilm A, Aw PPK, Bertrand D, Yeo GHT, Ong SH, Wong CH, Khor CC, Petric R, Hibberd ML, Nagarajan N. LoFreq: a sequence-quality aware, ultra-sensitive variant caller for uncovering cell-population heterogeneity from highthroughput sequencing datasets. Nucleic Acids Res. 2012;40:11189-201. 
58. Coll F, McNerney R, Preston MD, Guerra-Assunção JA, Warry A, HillCawthorne G, Mallard K, Nair M, Miranda A, Alves A, Perdigão J, Viveiros M, Portugal I, Hasan Z, Hasan R, Glynn JR, Martin N, Pain A, Clark TG. Rapid determination of anti-tuberculosis drug resistance from whole-genome sequences. Genome Medicine. 2015;7:51.

59. Li H. A statistical framework for SNP calling, mutation discovery, association mapping and population genetical parameter estimation from sequencing data. Bioinformatics (Oxford, England). 2011;27:2987-93.

60. Kozlov, A. M., A. J. Aberer, and A. Stamatakis. 2015. ExaML version 3: a too for phylogenomic analyses on supercomputers. Bioinformatics (Oxford, England) 31:2577-2579.

61. Coll F, McNerney R, Guerra-Assunção JA, Glynn JR, Perdigão J, Viveiros M, Portugal I, Pain A, Martin N, Clark TG. A robust SNP barcode for typing Mycobacterium tuberculosis complex strains. Nat Commun. 2014;5:4812.

62. Letunic I, Bork P. Interactive tree of life (iTOL) v3: an online tool for the display and annotation of phylogenetic and other trees. Nucleic Acids Res. 2016:44:W242-5

63. Ondimu, T. O., M. O. Grace, A. O. Samson, and S. A. Asito. 2017. Comparative study of smear microscopy, GeneXpert and culture and sensitivity assays in detection of mycobacterium tuberculosis on sputum samples among tuberculosis suspected cases in Nyamira County referral hospital. Mycobacterial diseases 7.

\section{Publisher's Note}

Springer Nature remains neutral with regard to jurisdictional claims in published maps and institutional affiliations.

Ready to submit your research? Choose BMC and benefit from:

- fast, convenient online submission

- thorough peer review by experienced researchers in your field

- rapid publication on acceptance

- support for research data, including large and complex data types

- gold Open Access which fosters wider collaboration and increased citations

- maximum visibility for your research: over $100 \mathrm{M}$ website views per year

At $\mathrm{BMC}$, research is always in progress.

Learn more biomedcentral.com/submissions 